strength as those ordinarily used in manufacture. Care must be taken, however, that the solvents are free from all matter not volatile at $100^{\circ} \mathrm{C}$.

[CONTRIbUtions from the CHEMICAL Laboratory OF CASE School oF APPLIED SCIHNCE, No. 39.]

\title{
COMPOSITION OF TEXAS PETROLEUM.
}

by Charles F. MaberY.

Received Fehruary 9, 5901

INDICATIONS of the presence of petroleum in Texas in several sections have been observed during the last thirty years, and many attempts have been made to obtain oil in sufficient quantities for the preparation of commercial products. But it is only within the last six years that oil has been found in sufficient amounts to encourage further development. The principal yield has been in the counties of Navarro, Bexar, Nacagdoches, and Hardin, and the chief supply has come from the Corsicana field in Navarro County. In the early development of the Corsicana field a specimen of the oil was briefly examined by Thiele, ${ }^{1}$ who gave its specific gravity as 0.8296 , and the proportions in temperatures Fahrenheit in which it distilled. The resemblance of this oil to Pennsylvania and to Ohio petroleum alluded to by the author seems to be scarcely supported by the meager examination.

Corsicana oil was later examined by Richardson, ${ }^{2}$ who obtained percentages of carbon and hydrogen in the distillate $100^{\circ}-150^{\circ}$ at $25 \mathrm{~mm}$., corresponding to the series $\mathrm{C}_{n} \mathrm{H}_{2 n}$.

Another important section of the Texas oil field has recently been developed in Jefferson County, and it has suddenly become famous by the discovery of a large pool, under high pressure, that has furnished the phenomenal supply in the Iucas well. The surface indications in this section, in the vicinity of Sabine Pass, were such that this pool narrowly escaped previous Aiscovery by other prospectors. Oil has been obtained in smaller amounts for some time in this county, and the composition of one specimen was ascertained by Mabery and Buck. ${ }^{3}$ This oil was found to consist mainly of the series of hydrocarbons represented by the general symbols $\mathrm{C}_{n} \mathrm{H}_{2 \mathrm{n}-2}$ and $\mathrm{C}_{\mathrm{n}} \mathrm{H}_{2 n-4}$. It was an extremely heavy petroleum, specific gravity 0.9500 . Scarcely any distilled below

1 Am. Chem. J., 22, 489.

2 J. Soc. Chem. Ind., February, 1900.

3 This Journa1, 22, 553 . 
$250^{\circ}$ atmospheric pressure. Having obtained a quantity of oil from the Lucas well before it was capped, I was interested to ascertain its composition. The well was drilled to a depth variously estimated between I000 and I 300 feet at a point where the surface was approximately i roo feet above sea-level, consequently the oil pool was probably 200 feet below sea-level. A peculiar method of drilling was necessary in penetrating the wet surface soil and 400 feet of drift sand. When the oil was reached, the four-inch casing weighing 6 tons was driven out with such force that it was sent 200 feet into the air and the column of oil which followed escaped in such quantities that the daily output before the well was capped was estimated at 70,000 barrels.

When received fresh from the well this oil gave a strong odor of hydrogen sulphide. Its specific gravity at $20^{\circ}$ was 0.920 , corresponding to $22^{\circ} \mathrm{B}$., showing it to be heavier than the Corsicana oil, but not so heavy as other specimens of Texas oil examined in this laboratory. It is a high sulphur oil (2. I6 per cent.), perhaps the highest in sulphur of any petroleum I have examined. It contains considerable nitrogen, more than I per cent. Under atmospheric pressure, it distilled in the following proportions :

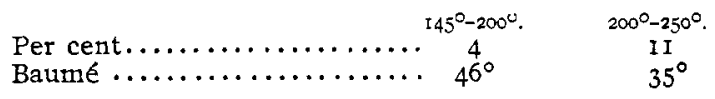

Under $14 \mathrm{~mm}$. it distilled as follows :

\begin{tabular}{|c|c|c|c|}
\hline Per cent $\ldots \ldots \ldots \ldots \ldots \ldots$ & $\begin{array}{c}95^{\circ}-100^{\circ} . \\
17\end{array}$ & $\begin{array}{c}150^{\circ}-200^{\circ} . \\
17 \\
170\end{array}$ & $\begin{array}{c}250^{\circ}-300^{\circ} \\
5^{I}\end{array}$ \\
\hline Baumé................ & $29^{\circ}$ & & \\
\hline
\end{tabular}

The vacuum distillation was continued until considerable proportions collected at certain temperatures. To determine the series, the distillates $\mathrm{I} 30^{\circ}-\mathrm{I} 35^{\circ}, 155^{\circ}-160^{\circ}$, I $90^{\circ}-\mathrm{I} 95^{\circ}$, were selected for examination. The crude fractions were thoroughly purified with concentrated and with fuming sulphuric acid, and washed with caustic soda. The fraction $130^{\circ}-135^{\circ}$ gave as its specific gravity at $20^{\circ}, 0.8553$, the fraction $155^{\circ}-160^{\circ}, 0.8746$, and the fraction $190^{\circ}-195^{\circ}, 0.8915$. To determine the series, combustions were made of each of these oils. The fraction $130^{\circ}-135^{\circ}$ gave 86.86 per cent. carbon, and I 3.27 per cent. hydrogen, which corresponds to the symbol $\mathrm{C}_{12} \mathrm{H}_{22}, 86.75$ per cent. carbon and $\mathrm{I} 3.25$ per cent. hydrogen. The molecular weight of this oil at the freezing-point of benzene was found to be 170. The formula $\mathrm{C}_{12} \mathrm{H}_{22}$ requires 160 . The fraction $155^{\circ}-160^{\circ}$ gave 86.26 per cent. 
carbon and 13.48 per cent. hydrogen; required for the formula $\mathrm{C}_{14} \mathrm{H}_{32}$, carbon 86.60 per cent., hydrogen $\mathrm{I} 3.40$ per cent. The molecular weight of this fraction at the freezing-point of benzene was found to be I94.I ; calculated for $\mathrm{C}_{14} \mathrm{H}_{26}$, I94. This formula was further confirmed by a determination of the index of refraction which gave $I .473$, corresponding to the molecular refraction 62.36; calculated for the formula $\mathrm{C}_{15} \mathrm{H}_{30}, 62.33$. A combustion of the fraction $190^{\circ}-195^{\circ}$ gave 87.26 per cent. carbon and $\mathrm{I} 2.54$ per cent. hydrogen. The formula $\mathrm{C}_{16} \mathrm{H}_{30}$ requires 87.03 per cent. carbon, I 2.97 per cent. hydrogen. The determination of the molecular weight of this fraction at the freezing-point of benzene gave 222.8 ; calculated for $\mathrm{C}_{16} \mathrm{H}_{30}, 222$. This formula was also confirmed by the index of refraction which gave 1.484 , corresponding to the molecular refraction 71.64 ; required for the formula $\mathrm{C}_{15} \mathrm{H}_{30}, 7 \mathrm{I} .54$. The principal hydrocarbons in this petroleum, therefore, are members of the series $\mathrm{C}_{n} \mathrm{H}_{2 n-2}$, the same series that Mabery and Buck found in the other petroleum mentioned above, in the lower portions. Since the hydrocarbons in the two oils were fractioned under different pressures, the corresponding differences in temperatures shows an agreement in percentage composition and in molecular weights.

The residue from the last distillation in vacuo gave as its specific gravity $14^{\circ}$ Baumé. This oil is, therefore, less rich in the heavier hydrocarbous that make the most valuable lubricators, and asphalts than the heavier Texas oil previously examined.

Since the hydrocarbons in this oil show no evidence of unsaturation, their structure is explained by the assumption of a double methylene ring and its derivatives. Such a structure would correspond to a dihexahydro diphenyl,<smiles>CCC=CC1CCC(C2CCCC2)C1</smiles>

The hydrocarbon $\mathrm{C}_{14} \mathrm{H}_{26}$ should be a dimethyl or an ethyl derivative, and the hydrocarbon $\mathrm{C}_{16} \mathrm{H}_{30}$ could contain a single butyl side chain, or an equivalent in methyl, ethyl, or propyl side-chains. This homologous series of hydrocarbons presents an interesting field for study, since so little is known about them. 
Mr. O. J. Sieplein, instructor, and Mr. A. H. Goldstein, student in this laboratory, have aided in the experimental work on this petroleum. Aid in carrying on this work was received from the C. M. Warren Fund for chemical research.

\section{NOTES.}

On Nitrometer Work. -The following work was done on the usual nitrometer, composed of a decomposing bulb and reservoir and the complement of a measuring tube, reduction tube and reservoir. The measuring tube had a capacity of $140 \mathrm{cc}$. The potassium nitrate used was Merck's, chemically pure, recrystallized. About 0.5 gram was used for each determination. The temperature of the laboratory, while the work was being done, was approximately $68^{\circ} \mathrm{F}$. The dry potassium nitrate was weighed out into tared weighing bottles and about I $_{5} \mathrm{cc}$. of sulphuric acid added. The bottles were then stoppered and set aside for about eighteen hours, or over night, by which time a clear solution was obtained, if the acid used was over 90 per cent. $\mathrm{H}_{2} \mathrm{SO}_{4}$, but if of less strength a residue, presumably of potassium sulphate, was left. The contents of the weighing-bottles were transferred to the decomposing bulb with the aid of a wash-bottle containing acid of the same strength as that used in the weighing bottles. In each determination $32 \mathrm{cc}$. of acid were used. The strengths of sulphuric acid used and the volume in cubic centimeters of nitric oxide (NO) per gram of potassium nitrate for each acid are as follows :

\begin{tabular}{|c|c|c|c|c|c|c|}
\hline \multirow{2}{*}{$\begin{array}{l}\text { Strength of } \\
\text { sulphuric acid } \\
\text { in per cent. }\end{array}$} & \multicolumn{6}{|c|}{ Cubic centimeters of nitric oxide per gram potassium nitrate. } \\
\hline & I. & II. & III. & IV. & v. & Average \\
\hline 98.03 & 222.0 & 221.8 & 222.0 & 222.3 & 222.3 & 222.08 \\
\hline 96.92 & 223.2 & 223.0 & $223 \cdot 3$ & $223 \cdot 3$ & ... & 223.2 \\
\hline 96.92 & 224.0 & $224 \cdot 3$ & 224.4 & 224.4 & 224.4 & $224 \cdot 3$ \\
\hline 95.14 & 225.1 & 224.8 & 225.0 & 225.2 & 225.0 & 225.0 \\
\hline 94.07 & 225.0 & 225.0 & 224.9 & 225.2 & 225.0 & 225.02 \\
\hline 93.05 & 225.1 & 225.0 & 224.8 & 224.9 & 225.0 & 224.96 \\
\hline 90.90 & 225.0 & 224.9 & 224.9 & 225.0 & 225.0 & 224.96 \\
\hline 85.04 & 225.3 & 225 . I & 225.3 & 225.0 & 225.3 & 225.2 \\
\hline 8o.I4 & 226.2 & 226.0 & 226.2 & 226.2 & 226.0 & 226 . I \\
\hline
\end{tabular}

A difference of $4.02 \mathrm{cc}$. of nitric oxide is thus obtained by the use of the strongest and weakest acids. It seems probable that this is due to the varying absorptive powers for nitric oxide, of the different strengths of sulphuric acid used. 